\title{
Cedrol, a malaria mosquito oviposition attractant is produced by fungi isolated from rhizomes of the grass Cyperus rotundus
}

\author{
Lynda K. Eneh ${ }^{1}$, Hiromi Saijo ${ }^{1,2}$, Anna-Karin Borg-Karlson' ${ }^{1}$ Jenny M. Lindh ${ }^{1 *}$ and Gunaratna Kuttuva Rajarao ${ }^{3}$
}

\begin{abstract}
Background: Cedrol, a sesquiterpene alcohol, is the first identified oviposition attractant for African malaria vectors. Finding the natural source of this compound might help to elucidate why Anopheles gambiae and Anopheles arabiensis prefer to lay eggs in habitats containing it. Previous studies suggest that cedrol may be a fungal metabolite and the essential oil of grass rhizomes have been described to contain a high amount of different sesquiterpenes.

Results: Rhizomes of the grass Cyperus rotundus were collected in a natural malaria mosquito breeding site. Two fungi were isolated from an aqueous infusion with these rhizomes. They were identified as Fusarium falciforme and a species in the Fusarium fujikuroi species complex. Volatile compounds were collected from the headspace above fungal cultures on Tenax traps which were analysed by gas chromatography-mass spectrometry (GCMS). Cedrol and a cedrol isomer were detected in the headspace above the F. fujikuroi culture, while only cedrol was detected above the F. falciforme culture.
\end{abstract}

Conclusion: Cedrol an oviposition attractant for African malaria vectors is produced by two fungi species isolated from grass rhizomes collected from a natural mosquito breeding site.

Keywords: Malaria, Oviposition attractant, Fungi, Rhizome, Cedrol

\section{Background}

Recently, the sesquiterpene alcohol cedrol was identified as an attractant for gravid female Anopheles gambiae mosquitoes that are vectors of the human malaria parasites [1]. The compound was detected as a volatile from an infusion made with water and soil taken from a natural Anopheles breeding site. A similar soil infusion had previously been shown to mediate an increased oviposition response in cage bioassays when incubated for 6 days compared to 2 and 4 days [2]. In addition, a 6 day old aqueous infusion with soil from the same site was shown to attract An. gambiae females to gravid traps in semi-field settings [3]. Furthermore, cedrol was detected in higher amount from a non-autoclaved soil infusion compared to the same infusion that had

\footnotetext{
*Correspondence: jenlindh@kth.se

${ }^{1}$ Chemical Ecology Unit, Division of Organic Chemistry, KTH Royal Institute of Technology, Stockholm, Sweden

Full list of author information is available at the end of the article
}

been autoclaved [1]. These results suggested a possible microbial link and together with reports about sesquiterpenes as common fungal metabolites $[4,5]$ indicates that the cedrol released from the soil infusion may be of fungal origin.

Cyperus rotundus grass, also known as nut grass, was found growing in the natural Anopheles breeding site where the soil was collected in the previous studies [1-3]. Furthermore, essential oil from rhizomes of this grass has been reported to contain high amounts of sesquiterpenes [6] and cedrol has been found in rhizome extract of another grass species in the same genus, Cyperus articulates [7]. Based on these studies it was hypothesized that fungi associated with $C$. rotundus rhizomes may be the source of the oviposition attractant cedrol. To test this, fungi were isolated from rhizomes of $C$. rotundus grass collected from the same natural Anopheles breeding site used for the soil infusion studies described above. Furthermore, volatiles were collected from the headspace 
above cultures of these fungi and analysed on a gas chromatograph coupled to a mass spectrometer.

\section{Methods}

\section{Fungi isolation and identification}

Soil with C. rotundus rhizomes (Fig. 1) was collected from a malaria mosquito breeding site at the international centre of insect physiology and ecology-the Thomas Odhiambo campus in Mbita, Western Kenyaand transported to Sweden. The rhizomes were harvested and washed in sterile water five times to remove any traces of soil and then incubated in sterile water at a concentration of $70 \mathrm{~g} / \mathrm{l}$ (rhizome-water infusion). The infusion was allowed to stand for 2 days (R2D) or for 6 days (R6D) at room temperature $\left(22 \pm 2{ }^{\circ} \mathrm{C}\right)$. Samples of the rhizome infusion $(100 \mu \mathrm{l})$ were spread on YEG agar plates, which were incubated at room temperature for 2-6 days.

Yeast extract glucose (YEG) agar was prepared by adding $4 \mathrm{~g}$ of yeast extract (Applichem: Chemtronica $\mathrm{AB}$, Stockholm Sweden), $4 \mathrm{~g}$ of D-glucose (Applichem; Chemtronica $\mathrm{AB}$, Stockholm Sweden) and $15 \mathrm{~g}$ agar (Fluka analytical, Sigma, Stockholm Sweden) to $1 \mathrm{~L}$ of deionized water. This mixture was sterilized using an autoclave at $121{ }^{\circ} \mathrm{C}$ for $20 \mathrm{~min}$. YEG broth was prepared the same way but without the agar.

Single isolates from the plates were transferred to new YEG agar plates and incubated at room temperature for 2-6 days and repeated sub-culturing until single isolates were obtained and confirmed by observation under a microscope. The isolates were sent to CBS-KNAW Fungal Biodiversity Centre for identification (Centraalbureau voor Schimmelcultures, Netherlands).

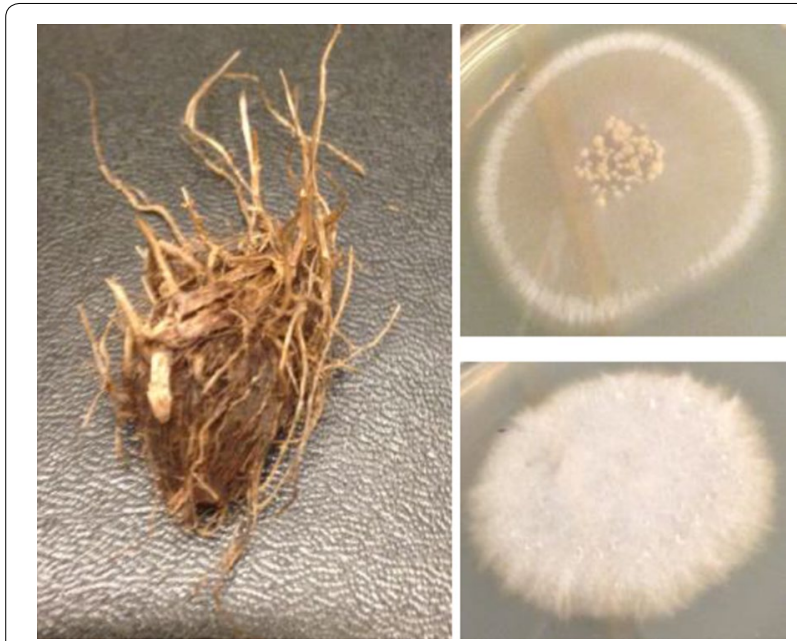

Fig. 1 Rhizome of Cyperus rotundus and the two fungal cultures; top: F. falciforme Carrion, below: a species in the F. fujikuroi species complex

\section{Headspace collections from fungal cultures}

The fungal isolates were inoculated into separate E-flasks $(500 \mathrm{ml})$ with $300 \mathrm{ml}$ YEG broth. Headspace samples were collected on Tenax traps from the headspace above fungal cultures after incubation for 6 days. The E-flask was fitted with a gas wash bottle head (QuickFit joined ware, Staffordshire, United Kingdom) for volatile collections. The traps were made from $25 \mathrm{mg}$ of Tenax ${ }^{\circledR}$ TA polymer (60-80 mesh, Supelco, Bellefonte, PA, USA), placed in GERSTEL-Twister Desorption glass liners (GERSTEL, Muelheim an der Ruhr, Germany). The polymer was held in place with glass wool (Supelco, Bellefonte, PA, USA) on each side. The traps were washed 10 times with $200 \mu \mathrm{l}$ of methyl tertbutyl ether (MTBE) and sealed with polytetrafluorethylene (PTFE) tape and placed in oven at $40{ }^{\circ} \mathrm{C}$ for $4 \mathrm{~h}$ before use. Charcoal filtered air was pumped into the E-flasks at a rate of $0.1 \mathrm{l} / \mathrm{min}$ and drawn out at the same rate through a Tenax trap. The traps were sealed with PTFE tape after collection and stored at $-80{ }^{\circ} \mathrm{C}$. E-flasks containing $300 \mathrm{ml}$ of sterile YEG agar and empty E-flasks were sampled the same way and utilized as controls for culture medium and Tenax trap background volatiles.

\section{Gas chromatography-mass spectrometry (GC-MS) analysis} Tenax traps with fungal headspace collections were analysed on an Agilent 7890A gas chromatograph connected to an Agilent 5975C inert MSD with Triple Axis detector mass spectrometer (Agilent, Santa Clara CA, USA). The GCMS system was fitted with a GERSTEL Multi-Purpose Sampler (MPS: Gerstel GmbH \& Co. KG, Mülheim an der Ruhr, Germany). The GC capillary column utilized was an Agilent's HP-5MS column (5\% phenyl and $95 \%$ dimethyl polysiloxane, $30 \mathrm{~m}, 250 \mu \mathrm{m}$ internal diameter and $0.25 \mu \mathrm{m}$ film thickness). Prior to analysis one microliter heptyl acetate $(3.16 \mathrm{ng} / \mu \mathrm{l})$ was added to the Tenax trap in the GERSTEL thermal desorption unit (TDU) followed by thermal desorption of traps in splitless mode at an initial temperature of $40{ }^{\circ} \mathrm{C}$ which was then increased by $120^{\circ} \mathrm{C} / \mathrm{min}$ to $270{ }^{\circ} \mathrm{C}$, the end temperature was held for $5 \mathrm{~min}$. The desorbed volatiles were focused in a GERSTEL CIS inlet at $10^{\circ} \mathrm{C}$. The CIS inlet operated in splitless mode was then heated at a rate of $12{ }^{\circ} \mathrm{C} / \mathrm{s}$ to $280{ }^{\circ} \mathrm{C}$ during which the volatiles were transferred to the column. The MS at full scan identified mass ranges from 30 to $400 \mathrm{~m} / \mathrm{z}$ with electron ionization at $70 \mathrm{eV}$ and ion source temperature at $230{ }^{\circ} \mathrm{C}$.

The GC-MS data were analysed with Agilent's enhanced Chemstation software version E.02.01.1177. The data were screened for two of the main MS ions of cedrol $(95,150)$. The identified peak was confirmed to be cedrol by comparing the retention time and mass 
spectra to a sample of an authentic standard of cedrol $[(+)$-cedrol, $\geq 99.0 \%$ sum of enantiomers, GC, optical activity $\alpha_{\mathrm{D}}^{20}+10.5 \pm 1^{\circ}$, Sigma-Aldrich Sweden AB, Stockholm, Sweden] analysed using the same GCMS settings as described above. Epi-cedrol and $\alpha$-acorenol were identified based on comparison of the mass spectra to mass spectra in the NIST 08 library and in Brock et al. [8].

\section{Results and discussion}

Two fungi were isolated from the aqueous rhizome infusion and identified as a species in the Fusarium fujikuroi species complex and Fusarium falciforme (Fig. 1). Fusarium is a large genus of filamentous fungi that are widely distributed in soil, often associated with plants. F. fujikuroi species can be pathogens for rice [9] and cause bakanae disease ("foolish seedling disease") through metabolism of high amounts of gibberellins, which are plant hormones that promotes growth. A fungus in the $F$. fujikuroi species complex has previously been reported to produce a large range of volatile compounds where the majority were sesqui- and diterpenes, including well known precursors of gibberellins $[8,10]$. The main sesquiterpene was identified as a-acorenol, however also small amounts of cedrol and epi-cedrol were detected $[8,10]$. All three of these compounds were also detected as metabolites of the F. fujikuroi isolate included in this study (Fig. 2) while only cedrol was detected above the F. falciforme culture. It is possible that a longer incubation time or modified culture conditions might enhance the production of cedrol by these fungal species. It would be interesting to test the response of An. gambiae mosquitoes to these compounds and fungal cultures in oviposition bioassays [11]. Cedrol is well known as a component of essential oils of Cupressus and Juniperus species and have been found in a variety of other plants [7, 12-14]. Further studies are needed to elucidate if fungi associated with the plants are involved in the metabolism of the compound for any of these species.

Other fungi such as Beauveria bassiana have been shown to produce spores that are attractive to host seeking Anopheles stephensi mosquitoes [15]. This agrees with this study that fungi can produce cues that attract mosquitoes. In fact, fungal volatiles and insect orientation may be a common ecological phenomenon, for instance it has been observed that volatiles like 2-phenylethanol and 2-methyl-1-butanol from Aureobasidium pullulans are attractive to different insect taxa [16]. Furthermore, volatiles from several fungi were tested as oviposition attractants of female yellow peach moths and the result suggested that the compounds can be used in gravid traps to monitor oviposition [17].

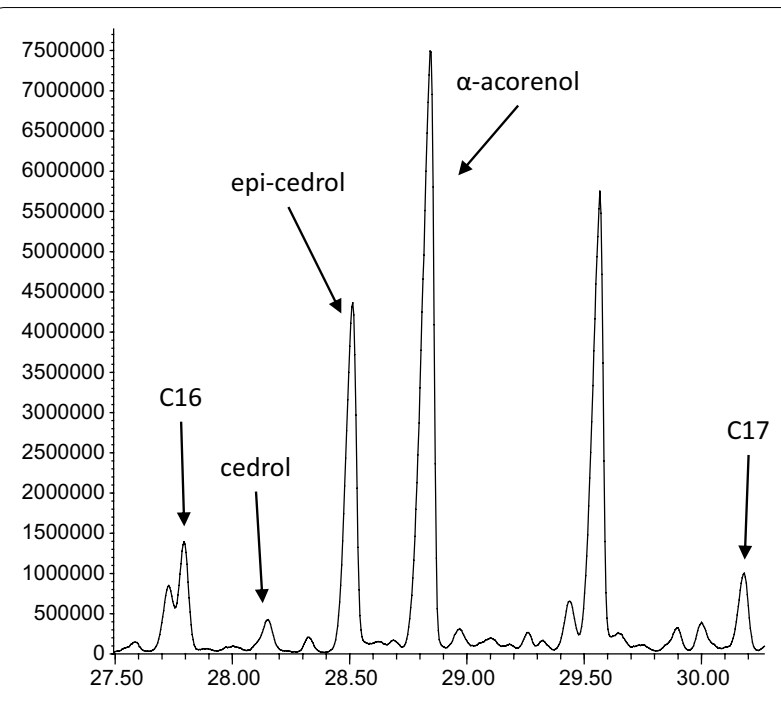

Fig. 2 Cedrol, epi-cedrol and a-acorenol detected in the headspace above a F. fujikuroi culture

\section{Conclusion}

Cedrol, the first identified oviposition attractant for $A n$. gambiae s.s. and An. arabiensis females was identified as a metabolite of two fungi species in the Fusarium genus. These fungi were isolated from $C$. rotundus rhizomes collected from a natural Anopheles oviposition site. This finding may be utilized in future studies to understand why malaria mosquitoes utilize cedrol as an attractant and how the compound and possibly the grass species may influence malaria mosquito ecology. Such knowledge could be utilized in development of novel control strategies targeting gravid females.

\section{Authors' contributions}

LKE conceived and designed the experiments. JL and GKR revised the experimental design. LKE and HS performed the experiments. LKE, HS, JL, GKR, AKBK analysed the data. LKE wrote the first draft of the paper; all authors contributed to the final draft. All authors read and approved the final manuscript.

\section{Author details}

${ }^{1}$ Chemical Ecology Unit, Division of Organic Chemistry, KTH Royal Institute of Technology, Stockholm, Sweden. ${ }^{2}$ Forest Products Group, Faculty of Agriculture, Yamagata University, Tsuruoka, Japan. ${ }^{3}$ Division of Industrial Biotechnology, School of Biotechnology, KTH Royal Institute of Technology, Stockholm, Sweden.

\section{Acknowledgements}

Authors thank Paul Ouma for technical assistance and the first observation of the presence of grass rhizomes in the soil samples. The project was funded by Swedish Research Council grant no SWE-2010-129 (AKBK, GKR, LKE) and the National Institute of Health (NIH) grant no. R01Al082537 (AKBK, JL). The funders had no role in study design, data collection and interpretation, or the decision to submit the work for publication.

\section{Competing interests}

The authors declare that they have no competing interests.

\section{Availability of data and materials}

The data supporting this paper will be made available upon request. 
Received: 31 May 2016 Accepted: 13 September 2016

Published online: 17 September 2016

\section{References}

1. Lindh J, Okal M, Herrera-Varela M, Borg-Karlson AK, Torto B, Lindsay S, et al. Discovery of an oviposition attractant for gravid malaria vectors of the Anopheles gambiae species complex. Malar J. 2015;14:1.

2. Herrera-Varela M, Lindh J, Lindsay SW, Fillinger U. Habitat discrimination by gravid Anopheles gambiae sensu lato-a push-pull system. Malar J. 2014;13:133.

3. Okal MN, Herrera-Varela M, Ouma P, Torto B, Lindsay SW, Lindh JM, et al. Analysing chemical attraction of gravid Anopheles gambiae sensu stricto with modified BG-sentinel traps. Parasit Vectors. 2015;8:301.

4. Kramer R, Abraham W-R. Volatile sesquiterpenes from fungi: what are they good for? Phytochem Rev. 2012;11:15-37.

5. Brasch J, Horter F, Fritsch D, Beck-Jendroschek V, Tröger A, Francke W. Acyclic sesquiterpenes released by Candida albicans inhibit growth of dermatophytes. Med Mycol. 2014;52:46-55.

6. Kilani S, Ledauphin J, Bouhlel I, Ben Sghaier M, Boubaker J, Skandrani I, et al. Comparative study of Cyperus rotundus essential oil by a modified GC/MS analysis method. Evaluation of its antioxidant, cytotoxic, and apoptotic effects. Chem Biodivers. 2008;5:729-42.

7. Olawore NO, Usman LA, Ogunwande IA, Adeleke KA. Constituents of rhizome essential oils of two types of Cyperus articulatus L. grown in Nigeria. J Essent Oil Res. 2006;18:604-6.

8. Brock NL, Huss K, Tudzynski B, Dickschat JS. Genetic dissection of sesquiterpene biosynthesis by Fusarium fujikuroi. ChemBioChem. 2013;14:311-5.
9. Wulff EG, Sørensen JL, Lübeck M, Nielsen KF, Thrane U, Torp J. Fusarium spp. associated with rice Bakanae: ecology, genetic diversity, pathogenicity and toxigenicity. Environ Microbiol. 2010;12:649-57.

10. Brock NL, Tudzynski B, Dickschat JS. Biosynthesis of sesqui- and diterpenes by the gibberellin producer Fusarium fujikuroi. ChemBioChem. 2011;12:2667-76.

11. Okal MN, Lindh JM, Torr SJ, Masinde E, Orindi B, Lindsay SW, et al. Analysing the oviposition behaviour of malaria mosquitoes: design considerations for improving two-choice egg count experiments. Malar J. 2015;14:250.

12. Khwatenge IL. Isolation, identification and biodiversity of air-borne organic volatile semiochemicals for Chilo partellus for Zea mays Sorghum bicolor seedlings. Nairobi: University of Nairobi Jomo Kenyatta Memorial Library: University of Nairobi; 1999. p. 124.

13. Mercke P, Crock J, Croteau R, Brodelius PE. Cloning, expression, and characterization of epi-cedrol synthase, a sesquiterpene cyclase from Artemisia annua L. Arch Biochem Biophys. 1999;369:213-22.

14. Luczkiewicz M, Jesionek A, Kokotkiewicz A, Migas P, Mardarowicz M, Szreniawa-Sztajnert A, et al. Production of essential oils from in vitro cultures of Caryopteris species and comparison of their concentrations with in vivo plants. Acta Physiol Plant. 2015;37:1-11.

15. George J, Jenkins NE, Blanford S, Thomas MB, Baker TC. Malaria mosquitoes attracted by fatal fungus. PLoS ONE. 2013;8:e62632.

16. Davis TS, Landolt PJ. A survey of insect assemblages responding to volatiles from a ubiquitous fungus in an agricultural landscape. J Chem Ecol. 2013;39:860-8

17. Honda H, Ishiwatari T, Matsumoto Y. Fungal volatiles as oviposition attractants for the yellow peach moth Conogethes punctiferalis. J Insect Physiol. 1988;34:211.

\section{Submit your next manuscript to BioMed Central and we will help you at every step:}

- We accept pre-submission inquiries

- Our selector tool helps you to find the most relevant journal

- We provide round the clock customer support

- Convenient online submission

- Thorough peer review

- Inclusion in PubMed and all major indexing services

- Maximum visibility for your research

Submit your manuscript at www.biomedcentral.com/submit
() Biomed Central 